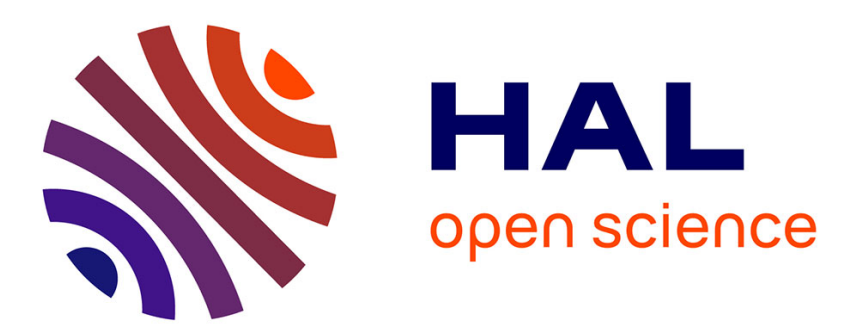

\title{
A remote laboratory to leverage motivation of learners to practice: an exploratory study about system administration
}

\author{
Julien Broisin, Rémi Venant, Philippe Vidal
}

\section{To cite this version:}

Julien Broisin, Rémi Venant, Philippe Vidal. A remote laboratory to leverage motivation of learners to practice: an exploratory study about system administration. 12th International Conference on Remote Engineering and Virtual Instrumentation (REV 2015), Feb 2015, Bangkok, Thailand. pp. 140-142. hal-01363341

\section{HAL Id: hal-01363341 https://hal.science/hal-01363341}

Submitted on 9 Sep 2016

HAL is a multi-disciplinary open access archive for the deposit and dissemination of scientific research documents, whether they are published or not. The documents may come from teaching and research institutions in France or abroad, or from public or private research centers.
L'archive ouverte pluridisciplinaire HAL, est destinée au dépôt et à la diffusion de documents scientifiques de niveau recherche, publiés ou non, émanant des établissements d'enseignement et de recherche français ou étrangers, des laboratoires publics ou privés. 


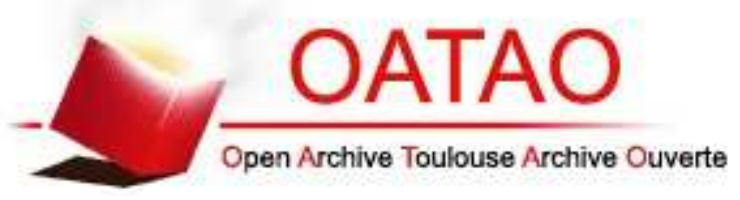

\section{Open Archive TOULOUSE Archive Ouverte (OATAO)}

OATAO is an open access repository that collects the work of Toulouse researchers and makes it freely available over the web where possible.

This is an author-deposited version published in : http://oatao.univ-toulouse.fr/ Eprints ID : 15339

The contribution was presented at REV 2015 :

http://www.rev-conference.org/REV2015/cfp_rev2015.php

To cite this version : Broisin, Julien and Venant, Rémi and Vidal, Philippe A remote laboratory to leverage motivation of learners to practice: an exploratory study about system administration. (2015) In: 12th International Conference on Remote Engineering and Virtual Instrumentation (REV 2015), 24 February 2015 - 26 February 2015 (Bangkok, Thailand).

Any correspondence concerning this service should be sent to the repository administrator: staff-oatao@listes-diff.inp-toulouse.fr 


\title{
A remote laboratory to leverage motivation of learners to practice: an exploratory study about system administration
}

\author{
Julien Broisin, Rémi Venant, Philippe Vidal \\ University of Toulouse \\ Institut de Recherche en Informatique de Toulouse-IRIT \\ Toulouse, France \\ \{broisin,venant,vidal\}@irit.fr
}

\begin{abstract}
This paper introduces a framework dedicated to online practical activities. Our remote laboratory is based on a distributed architecture composed of three layers: the learning interface is dedicated to end-users; the laboratory layer hosts the resources on which learners, teachers and tutors perform remote actions; the middleware layer acts as a broker between the two previous layers and embeds various control and learning services. The originality of our framework stands on: (1) a standard to control and supervise the resources of the remote laboratory, (2) the tracking of all users' activities at a low level of granularity (including both actions performed on the remote resources, as well as those resulting from the invocation of the learning services) so that various pedagogical features can be further designed, and (3) its independence regarding the learning domain to be learned. An implementation of the framework based on open source software and dedicated to computer engineering is exposed, allowing for an exploratory study involving 139 students enrolled in the first year of a computer science degree. The results of this study are discussed, and suggest a positive effect of our framework on motivation of learners when they come to learn system administration.
\end{abstract}

Index Terms - computer science engineering, exploratory study, human computer interface, remote supervision and control systems, virtual and remote laboratory.

\section{INTRODUCTION}

Hands-on lab works represent important learning activities for engineering education, especially when learners aim at reaching specific pedagogical objectives [1]. In the Technology Enhanced Learning (TEL) context, there is great demand on virtual and remote laboratories to benefit from their pedagogic and economic advantages [2].

This paper introduces such a remote laboratory, and is organized as follows: section II exposes our generic (i.e. independent from a specific learning domain) framework, whereas in section III we focus on an implementation dedicated to computer science education and expose the human computer interface (HCI) offered to students; the results of an exploratory study based on this environment are presented in section IV. A discussion comparing our approach with the main projects and initiatives offering access to a remote laboratory constitutes the section V.

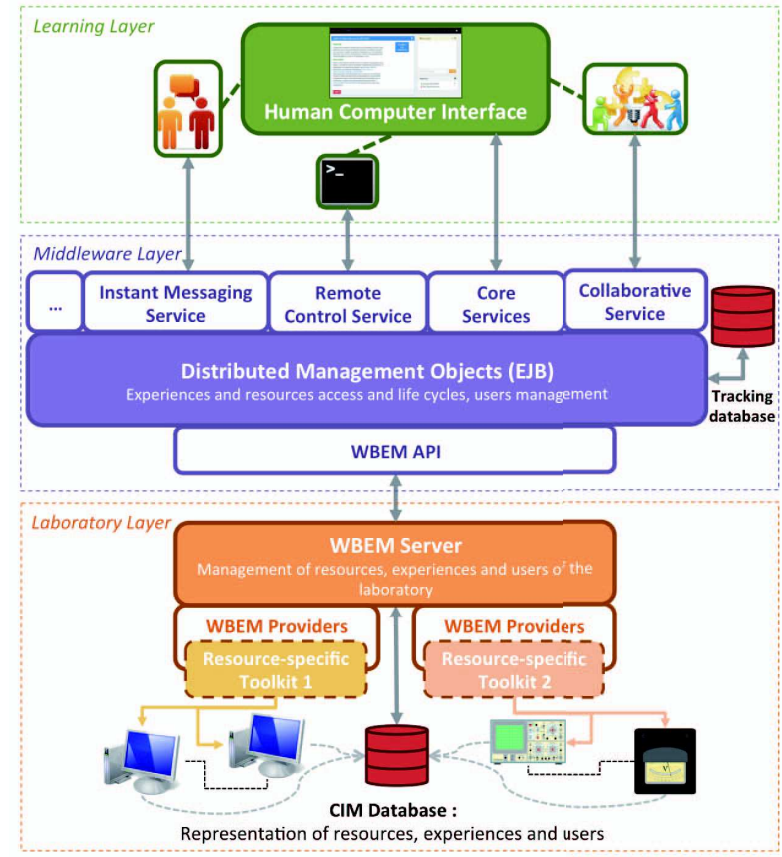

Figure 1. The big picture of our framework

Finally, some concluding remarks and perspectives represent the focus of section VI.

\section{OUR REMOTE LABORATORY FRAMEWORK}

The distributed architecture of our framework illustrated on Fig. 1 is composed of three layers.

The learning layer represents the Human Computer Interface (HCI) dedicated to end-users (i.e. teachers, learners and tutors). This HCI is composed of various widgets and components to communicate and exploit the set of services exposed by the middleware layer.

The laboratory layer is responsible for the management of physical and/or virtual resources manipulated by endusers of the learning layer, and of the accreditations offered to these users on these resources. To ensure these tasks, the laboratory layer is based upon the Distributed Management Task Force standardized approach to unify the management of computing environments: a set of models offers a representation describing the (state of the) resources, experiences and users of the laboratories [3], whereas some components (called WBEM Providers on 
Fig.1) concretely act on the resources according to the instructions they receive through the manager (called WBEM Server on Fig. 1) [4].

The middleware layer acts as a broker between the learning and the laboratory layers to offer a transparent communication between end-users and resources. On the one hand, it exposes learning services to the upper layer, orchestrated by a set of distributed objects; on the other hand, control instructions are forwarded to the lower layer through a dedicated API. In addition, the middleware records all users' activities: the actions performed on the remote resources of the laboratory, as well as those resulting form the invocation of the learning services.

\section{IMPLEMENTATION}

The above framework has been implemented for computer education to make accessible (interconnected) virtual machines to students: the learning layer was developed using the AngularJS and Bootstrap frameworks; the middleware layer stands on JavaEE to provide SOAP/REST/WebSocket access to the services appearing on Fig. 1, and adopts MySQL for the tracking database; the laboratory layer integrates OpenPegasus [5] to manage the virtual machines (VM) deployed under the Xen hypervisor.

The HCI dedicated to learners is illustrated on Fig.2. The main panel offers a tab-based navigation to access the various virtual machines of a practical session; students are able to start/stop/restart each of the remote computers, and to run commands and programs through a web Terminal. In addition, students are offered the opportunity to share questions, ideas and points of view through an instant messaging system. The chat service of the HCI has been developed using JavaEE technologies, and implements a Web Socket interface to communicate with the matching Enterprise JavaBean hosted by the middleware layer. This EJB records all chat posts into the tracking database mentioned in the previous section, so that additional services such as automatic and/or human tutoring, collaborative learning or understanding of the learning process can be built on top of these data.

The chat we implemented supports two types of rooms: a public room allows all users (i.e. students, teachers and tutors) to post messages, whereas a private room is attached to a given experiment. In the last case, only students invited in the given experiment are able to communicate. Two types of discussions can thus take place: the public room is appropriated for general discussions related to theoretical knowledge required to complete the objectives of the practical activity, whereas the private rooms help students regarding specific issues related to the actions that must be performed to correctly operate on the resources of the remote lab.

\section{EXPLORATORY STUDY}

At the time of writing this paper, our implementation has been experimented with 139 students enrolled in a course entitled "Introduction to computer systems" and included in the first year of a computer science curriculum. The pedagogical objectives of this course consist in learning the basis of the Linux operating system: learners must be able to (1) create, modify, delete, and move files and folders, (2) understand and manage the

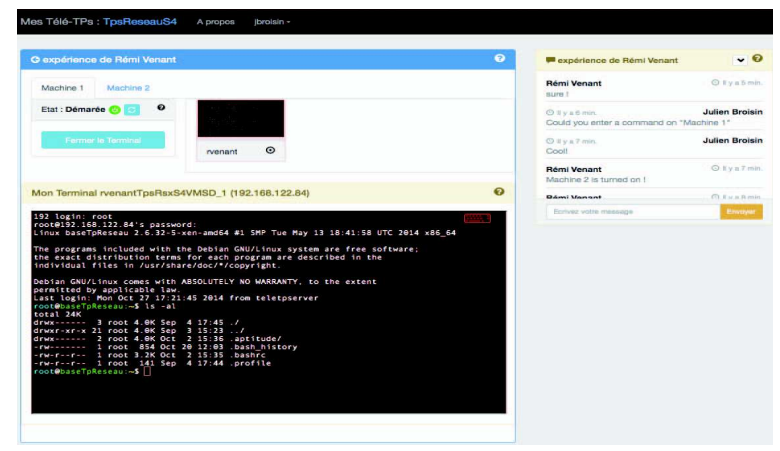

Figure 2. The HCI for computer education

concept of process, (3) write Shell scripts that facilitate the administration of this operating system.

To reach these objectives, one specific practical activity is proposed to students per week, and each student has to upload a report of the given activity on Sunday on the institution's learning management system (i.e. a Moodle server); let us note that late reports' submissions were allowed. Since computers running Linux are available within the institution, we did not force students to use our framework but gave them a brief presentation of the HCI during a face-to-face session only; the URL offering access to the system had also been integrated into the matching Moodle space.

Statistics about the usage of the framework during five weeks appear on Table I. Seventy one students created their own virtual machine, and each of them opened almost 7 sessions that lasted about 40 minutes, for a total number of commands higher than 770 . Interesting data are the days of the week where students used to connect to the system. They mainly worked during week-end, just before the report should be uploaded. The students also used the system on Monday, for late submissions, even if they were physically present within the institution and could work on "real" computers. Moreover, students posted 75 messages on the public chat room; due a lack of time, we did not analyze the content of these posts yet.

Finally, only two students worked collaboratively on the same virtual machine and exchanged 7 posts within the matching private chat room; this can be explained by the fact that (1) students had to upload their own report for a given activity, (2) students are not used to work collaboratively when they are not physically together, and (3) the practical activities proposed in this course were not advanced enough to require the help of peers.

\section{DISCUSSION}

Compared to mature and on-going projects $[6,7,8,9$, $10]$, the originality of our framework stands on its genericity, its standardized and unified approach to remotely manage resources of a lab, and the learning services it provides (i.e. the collaborative service).

\section{CONCLUDING REMARKS AND FUTURE WORKS}

We presented in this paper a domain-independent framework dedicated to virtual and remote laboratories, and showed how it can be implemented in the case of computer education. This implementation, validated by an exploratory study leaded in a blended-learning context, demonstrated that our proposal leverages learners' motivation when they come to practice. 
TABLE I.

STATISTICS OF THE EXPLORATORY STUDY

\begin{tabular}{|l|c|}
\hline \multicolumn{1}{|c|}{ Measured data } & Number of items \\
\hline Number of virtual machines & 71 \\
\hline Number of sessions (with 1h as a separator) & 477 \\
\hline Mean count of sessions per VM & 6,7 \\
\hline Mean duration per session (minutes) & 39 \\
\hline Mean count of commands per VM & 772 \\
\hline Days of the week where students are active & $\begin{array}{c}\text { Sat. (26\%), Sun. } \\
(16 \%), \text { Mon. (33\%) }\end{array}$ \\
\hline Number of chat messages in the public room & 75 \\
\hline Mean count of collaboration per experiment & 0,0145 \\
\hline Mean count of messages in a private room & 7 \\
\hline
\end{tabular}

Our future works will focus on end-users. First, we'll integrate into the learning layer an intuitive tool dedicated to teachers in order to offer them the opportunity to design practical activities automatically deployed on the remote laboratory. Then, the exploitation of the tracking data will constitute the main focus of these research works.

\section{ACKNOWLEDGMENT}

The authors wish to acknowledge support from Agence Nationale de la Recherche (Paris, France) under Program CONTINT 2010.

\section{REFERENCES}

[1] ACM/IEEE CS, 2004. Computer Engineering 2004, Curriculum Guidelines for Undergraduate degree Programs in Computer Engineering. A Report in the Computing Curricula Series, The Joint Task Force on Computing Curricula IEEE Computer Society, ACM, 2004.
[2] Steinemman M. A., Braun T., 2002. Remote versus Traditional Learning in a Computer Networks Laboratory. In Proceedings of IASTED International Conference on Communications and Computer Networks, Cambridge, USA.

[3] Distributed Management Task Force, 2014. DMTF Schema Documentation. Available at http://dmtf.org/sites/default/files/cim/ cim_schema_v2420/cim_schema_2.42.0Final-Doc.zip

[4] Distributed Management Task Force, 2014. Web-Based Enterprise Management initiative. Available at http://www.dmtf.org/ standards/wbem

[5] Open Pegasus. Available at http://www.openpegasus.org

[6] Gillet, D., De Jong, T., Sotirou, S., Salzmann, C. (2013). Personalised Learning Spaces and Federated Online Labs for STEM Education at School: Supporting Teacher Communities and Inquiry Learning. In Proceedings of 2013 IEEE Global Engineering Education Conference (pp. 769-773).

[7] Harward, V.J., del Alamo, J.A., Lerman, S.R., Bailey, P.H., Carpenter, J., DeLong, K., Felknor, C., Hardison, J., Harrison, B., Jabbour, I., Long, P.D., Tingting Mao, Naamani, L., Northridge, J., Schulz, M., Talavera, D., Varadharajan, C., Shaomin Wang, Yehia, K., Rabih Zbib, Zych, D. (2008). The iLab Shared Architecture: A Web Services Infrastructure to Build Communities of Internet Accessible Laboratories. Proceedings of the IEEE, 96(6), 931-950.

[8] Richter, T., Boehringer, D., \& Jeschke, S. (2011). LiLa: A European Project on Networked Experiments. Automation, Communication and Cybernetics in Science and Engineering 2009/2010, 307-317.

[9] Lowe, D., Berry, C., Murray, S., \& Lindsay, E. (2009). Adapting a Remote Laboratory Architecture to Support Collaboration and Supervision. In Proceedings of the 6th International Conference on Remote Engineering and Virtual Instrumentation (REV) (pp. 103108). International Association of Online Engineering.

[10] Sancristobal, E., Castro, M., Harward, J., Baley, P., DeLong, K., \& Hardison, J. (2010). Integration view of Web Labs and Learning Management Systems. In Proceedings of 2010 IEEE Global Engineering Education Conference (EDUCON) (pp. 1409-1417). 